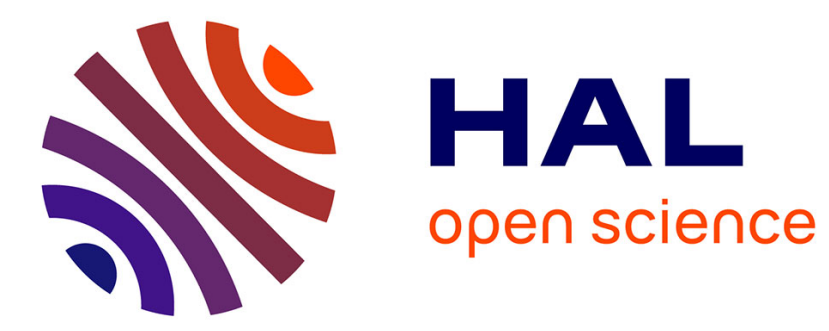

\title{
Effect of simulated rock climbing finger postures on force sharing among the fingers
}

\author{
Franck Quaine, Laurent Vigouroux, Luc Martin
}

\section{To cite this version:}

Franck Quaine, Laurent Vigouroux, Luc Martin. Effect of simulated rock climbing finger postures on force sharing among the fingers. Clinical Biomechanics, 2003. hal-01635429

\section{HAL Id: hal-01635429 \\ https://hal.science/hal-01635429}

Submitted on 16 Nov 2017

HAL is a multi-disciplinary open access archive for the deposit and dissemination of scientific research documents, whether they are published or not. The documents may come from teaching and research institutions in France or abroad, or from public or private research centers.
L'archive ouverte pluridisciplinaire HAL, est destinée au dépôt et à la diffusion de documents scientifiques de niveau recherche, publiés ou non, émanant des établissements d'enseignement et de recherche français ou étrangers, des laboratoires publics ou privés. 


\title{
Effect of simulated rock climbing finger postures on force sharing among the fingers
}

\author{
Franck Quaine ${ }^{*}$, Laurent Vigouroux, Luc Martin \\ EA 597, UFR APS, Université, Joseph Fourier, 1741 rue de la Piscine, BP 53 x, 38041 Grenoble cedex 9. France \\ Received 26 July 2002; accepted 25 February 2003
}

\begin{abstract}
Objective. To study the forces applied by each finger in different joint postures simulating rock climbing gripping postures. Design. Subjects in sitting posture applied fingertip forces perpendicular to horizontal force sensors in three different finger postures.

Background. Data provided by the literature indicate that middle and ring finger are commonly injured. However, no quantitative assessment of the forces applied by each finger related to the joint postures has been made.

Methods. Six elite rock climbers performed finger flexion in a single-finger task and a four-finger task. The tests were conducted in an extended posture, a curved posture (the joints belonging to the finger were flexed) and an intermediate posture (the joints were flexed, except the distal one which was fully extended). Each fingertip force was cxpressed in absolute value and in percentage of the maximal force capacity of the finger.

Results. The greater force was applied by the middle finger $(20.8 \mathrm{~N})$, whatever the posture. The relative involvement amounted to $105 \%$ for the ring finger in the curved posture.

Conclusions. The great force applicd by the middle finger and the great relative involvement of the ring finger in the curved posture seem to be the main factors of injuries of these fingers.
\end{abstract}

\section{Relevance}

The analysis of force sharing among the fingers during different joint postures mimicking rock climbing is essential to a better understanding of finger injuries.

(c) 2003 Elsevier Science Ltd. All rights reserved.

Keywords: Rock climbing; Force sharing; Fingertip force

\section{Introduction}

There has been remarkable development in the scope and quality of rock climbing during the last couple of years. In this activity, the hands are used as tools for the ascent and many of the external forces applied upon the fingers are distributed through the wrist, elbow and shoulder (Hass and Meyers, 1995; Quaine et al., 1997). Three quarters of elite and recreational sport climbers suffer from injuries at the upper extremities (Rooks, 1997). Sixty percent of these injuries involve the hand

\footnotetext{
"Corresponding author.

E-mail address: franck.quaine(a) ujf-grenoble.fr (F. Quaine).
}

and $40 \%$ of elite climbers have signs of failure to the A2 pulley (Bollen and Gunson, 1990). Failure to the A2 pulley arises when the flexor tendon sheaths are overloaded. This often occurs when the climber moves either to or from a small hold. Failure is largely acquired as a function of the grip techniques, the middle and ring fingers being most commonly injured (Schweizer, 2001). The pathomechanics of the rupture of flexor tendon pulleys is well described on cadaveric fingers (Sharkey et al., 1998) but is unknown during climbing, since no study has analyzed the forces applied by the fingers. We hypothesized that the middle and ring fingers are commonly damaged because they apply greater fingertip forces. The purpose of this study was to examine the forces applied by each finger in various simulated postures used in rock climbing. 


\section{Methods}

Six elite males rock climbers participated in the study [age: 22 (SD 1.4)years; height: 177.4 (SD 4.5$) \mathrm{cm}$; body mass: 65.6 (SD 2) kg; hand length from the middle fingertip to the distal crease of the wrist with the hand extended: 19 (SD 1.5) cm]. All subjects have been practising for ten years on average (five times per week). They signed an informed consent in accordance to the University guideline.

\subsection{Apparatus}

Since a previous work (Quaine et al., 1997) shows that high postural constraints associated to postural balance in rock climbing induce significant intra and intersubject supporting force variability, the subjects sat on a chair. In this case, the postural constraints are insignificant and it was easy to control and modify the grip posture for each subject. A device (Fig. 1) was assembled in the global reference system $(O, x, y)$. A vice was used to stabilize the upper arm. A clamp was used to stabilize the palm of the hand. The wrist was positioned at $40^{\circ}$ of extension. The upper arm was at $45^{\circ}$ of abduction, the elbow joint being flexed at $90^{\circ}$. A digital camera (Sony, DSC-S70) located $0.70 \mathrm{~m}$ above the device was used to control the finger posture. It measured the sagittal Index finger posture. Two markers per segment were used. The markers were aligned with the longitudinal axis of the segment. The angle of intersection of the lines of adjacent segments defined the joint angles. The angles were assumed to be similar for the four fingers. An extended finger displayed $180^{\circ}$ joint angles.

Four parallel mono-axial load cells (Schlumberger, model CD-750, Vélizy villacoublay cedex France) were used for vertical force measurement (see (Valero-Cuevas et al., 2000) for details). Steel plates $(20 \mathrm{~mm} \times 15 \mathrm{~mm})$ were fastened to the four load cells, providing finger contact areas. The space between the plates was $4 \mathrm{~mm}$. The pitch between the fingers was $19 \mathrm{~mm}$. The thumb did not act against any support as an additional gripping force.

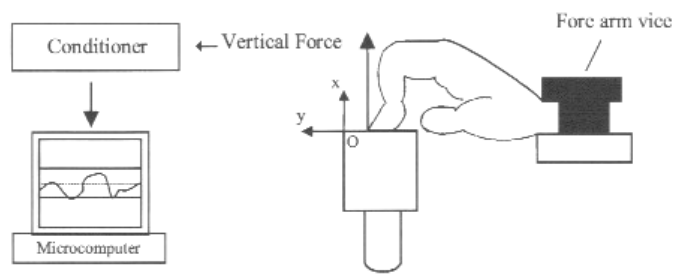

Fig. 1. Experimental setup. The posture corresponds to the 'crimp' posture in the text.

\subsection{Data processing}

Subjects warmed up on the device by carrying out a series of one hundred contractions for $5 \mathrm{~s}$ at $10 \mathrm{~N}$ (Schweizer, 2001). They were then asked to press the force sensors at maximal intensity with the index $(I)$, middle $(M)$, ring $(R)$ and little $(L)$ finger separately and then the combination IMRL. Subjects were asked to perform fingertip forces in the vertical direction as requested by previous authors (Zatsiorsky et al., 1998).

Three trials for $8 \mathrm{~s}$ were required for each task. A 2 min resting period was allowed after each trial in order to avoid fatigue. The highest peak force generated during each trial was adopted as maximal voluntary contraction force (MVC).

The tests were conducted in three different finger postures (Fig. 2): The first posture was labeled REF in the text. It consisted in maintaining both distal and proximal interphalangeal joints (DIP and PIP) straight, and metacarpophalangeal joint (MCP) with $140^{\circ}$ of flexion (Zatsiorsky et al., 1998; Li et al., 1998; Danion et al., 2000). The second posture corresponded to the climber's "crimp" posture (labeled CRI) and was characterized by the hyperextension at $\operatorname{DIP}\left(210^{\circ}\right)$, and $100^{\circ}$ and $160^{\circ}$ of flexion at PIP and MCP. The third posture was the climber's "slope" posture (labeled SLO), where DIP, PIP and MCP were flexed at $150^{\circ}, 160^{\circ}$ and $150^{\circ}$ respectively. These postures have been described previously and the angles are frequently used during climbing (Schweizer, 2001).

\subsection{Calculated parameters}

Single-fingertip force. It is the maximal force generated by a finger in the single-finger task: $F_{i}$ with $i=I, M$, $R$ and $L$.

Four-fingertip force. It is the maximal force produced by an individual finger in the four- finger task: $F_{\mathrm{i}}^{\mathrm{IMRL}}$ with $i=I, M, R$ and $L$.

The resultant four-fingertip force was calculated as: $F_{\max }^{\mathrm{IMRL}}=\sum_{\mathrm{i}} F_{\mathrm{i}}^{\mathrm{IMRL}}$ with $i=I, M, R$ and $L$.

Relative involvement of each finger. It was defined as the percentage of maximal force produced by an indi-

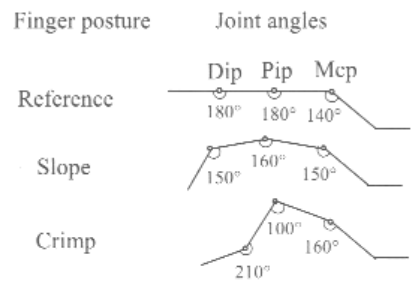

Fig. 2. Simulated finger postures. Dip and Pip correspond to the distal and proximal interphalangeal joints, Mcp corresponds to the metacarpophaleangeal joint. 
vidual finger in the four-finger task compared with the maximal force generated by the same finger in the singlefinger task as: $C_{i}=\left(F_{\mathrm{i}}^{\mathrm{IMRL}} / F_{\mathrm{i}}\right) \times 100 \%$ where $i$ represents the involved finger in the task.

\subsection{Statistical analysis}

Descriptive statistics are means and standard deviations. A one-factor ANOVA (Posture) with repeated measures was used to analyze the differences in resultant external force. Two-factor ANovas with repeated measures $(3 \times 4$, Posture $\times$ Finger $)$ were used to analyze the force applied by each finger during the single and fourfingertip tasks in the different postures. A level of $P<0.05$ was considered to be statistically significant.

\section{Results}

Single-fingertip force $F_{1}$ : Maximal forces for individual fingers in single-finger task are shown in Table 1. The ANOVA indicates a significant effect of Finger $(F(3,15)=14.6, P<0.00004)$. The maximal forces of the index and the middle finger were not statistically different and were greater than those of the ring and little finger. The force of the ring finger was not statistically different from the force of the little finger. No significant effect was observed for Posture, nor for the interaction Posture $\times$ Finger .

Resultant four-fingertip force $F_{\max }^{\mathrm{IMR} \text {. }}$ : The magnitude of the force is represented in Fig. 3. No significant difference was observed between the external force magnitudes performed in each posture. In REF, the mean force amounted to 58.6 (SD 21) N. In CRI and SLO, it amounted to 61.4 (SD 25) $\mathrm{N}$ and 65.9 (SD 14) $\mathrm{N}$ respectively,

Four-fingertip force $F_{\mathrm{i}}^{\mathrm{IMRL}}$ : The contribution of each finger to the resultant force is presented on Fig. 4. The ANOVA results show no significant effect of Posture. The mean external force magnitude was the same for each climber's grip, whatever the finger. A significant effect of Finger was observed $(F(3,15)=22.64, P<0.00008)$. The mean external force magnitude was different for each finger, whatever the posture. Newman-Keuls posthoc analysis among all the possible pairs of the four fingers shows that the force applied by the index was not statistically different from the one applied by the middle

Table 1

Mean (SD) single-fingertip force $(\mathrm{N})$ at the index $(I)$, middle $(M)$, ring $(R)$ and Little $(L)$ finger in the climber's "reference" (REF), "crimp" (CRI) and "slope" (SLO) postures $(n=6)$

\begin{tabular}{lllll}
\hline Postures & $I$ & $M$ & $R$ & $L$ \\
\hline REF & $34.7(8.6)$ & $33.2(9.5)$ & $18(6.7)$ & $11(3.9)$ \\
CRI & $21.5(7.3)$ & $20.7(6.3)$ & $15.1(6.3)$ & $15.2(2.8)$ \\
SLO & $22.8(8.5)$ & $23.5(8.4)$ & $11.9(5.7)$ & $16.7(3.7)$ \\
\hline
\end{tabular}

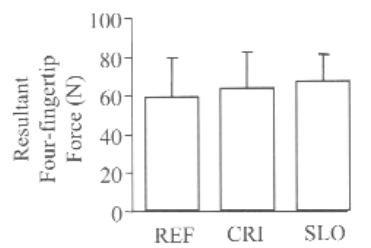

Fig. 3. Resultant four-fingertip force $\left(l_{\max }^{\mathrm{IMRL}}\right)$ in the climber's "refercnce" (REF), "crimp" (CRI) and "slope" (SLO) postures. Error bars indicate standard deviation.

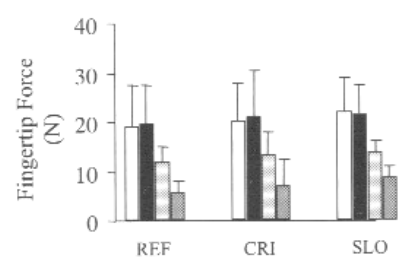

Fig. 4. Four-fingertip force $\left(F_{i}^{\mathrm{IMRI}}\right)$ applied beneath each finger $((\square)$ index; (回) middle; ( $\square$ ) ring; ( $\square$ ) little). Error bars indicate standard deviation. REF is the climber's "reference" posture, CRI the "crimp" posture and SLO the "slope" posture.

finger. They amounted to 20.5 (SD 7.33) $\mathrm{N}$ and 20.8 (SD 7.6) $\mathrm{N}$ respectively. They were statistically greater $(P<0.05)$ than the forces applied by the ring finger $[13.1$ (SD 3.4) N] and by the little finger [7.14 (SD 3.6) N].The interaction Posture $\times$ Finger showed no significant effect. This means that the external force magnitude increases similarly for each finger in the climber's "reference", "slope" and "crimp" postures.

Relative finger involvement $C_{i}$ : In the IMRL task, a significant Finger effect was observed $(F(3,15)=15.87$; $P<0.0001$ ), while no effect was observed for Posture. The interaction Posture $\times$ Finger (Fig. 5) was significant $(F(6,30)=2.6 ; P<0.03)$. Post-hoc analysis indicates that the climber's posture led to a drop in the relative finger involvement only for the middle [93 (SD 21) \%] and the ring $[105$ (SD 28) \%] fingers in the "slope" posture $(P<0.05)$. There was no significant change

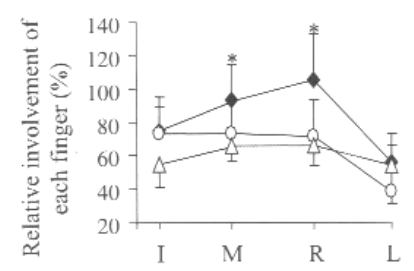

Fig. 5. Relative involvement of each finger $\left(C_{i}\right)$ for the index, middle, ring and little fingers $(I, M, R$ and $L)$ during the "slope" $(\bullet)$; "crimp" $(O)$ and "reference" $(\triangle)$ postures. Error bars indicate standard deviation. * indicates a significant difference between the relative involvement values for the middle and ring fingers and all others values $(P<0.05)$. 
concerning all the other values. They fluctuated between 38 (SD 28) \% and 75 (SD 20) \%.

\section{Discussion}

Our results show that the "crimp" and the "slope" posture do not affect the resultant force magnitude. This is conflicting with a previous report (Cutts and Bollen, 1993) which showed that the external force was greater during the climber's "crimp" posture than during the "slope" posture. However, the handgrip dynamometry presented in this study (Cutts and Bollen, 1993) involves an isometric contraction of the fingers in opposition to the thumb and the base of the hand, whereas the present study requires a different involvement of the fingers. The extended finger posture allows direct comparison with data in the literature (Li et al., 1998; Danion et al., 2000) and shows that the relative force distribution among the fingers is replicated in the present experiment. This means that rock climbers behave similarly to non-climber subjects (previously tested) when the external force is produced by all the fingers in an extended posture.

Moreover, the present results confirm that the fingers are not equally involved in the resultant force production. The greater involvement concerns the middle finger, followed by the index, the ring and then the little finger in each posture. This result validates a part only of our hypothesis: the most frequent middle finger injuries may occur because this finger applies the greater forces. Nevertheless, the explanation concerning the ring finger is less explicit. As previously mentioned ( $\mathrm{Li}$ et al., 1998), this finger applies reduced force in single-finger task, but the necessity to minimize unnecessary rotational moment with respect to the functional longitudinal axis of the hand ( $\mathrm{Li}$ et al., 1998) induces a great appeal on force production for this finger. This explains the high percentage of relative force in four-fingertip task and may explain the ring finger injuries in rock climbing.

\section{Conclusions}

The results show that the simulated climber's finger postures induce different force distributions among the four fingers when they act simultaneously. The most significant forces are always applied by the middle and index finger, followed by forces applied by the ring then by the little finger, which may explain the middle finger injuries. Furthermore, the relevant factor of injury for the ring finger in rock climbing seems to be the most significant relative force applied by this finger, particularly in the slope posture.

\section{References}

Bollen. S., Gunson, C., 1990. Hand injuries in competition climbers. Brit. J. Sport Med. 24. 16-18

Cutts, A., Bollen, S., 1993. Grip strength endurance in rock elimbers. Proc. Inst. Mech. Eng. 07, 87-92.

Danion. F.. Latash, M., Li, Z., Zatsiorsky, V.. 2000. The effect of fatigue on multifinger co-ordination in force production task in humans. J. Physiol. 523.2. 523532.

Hass. J.. Meyers. M., 1995. Rock climbing injuries. Sports Med. 20, 199-205.

Li, Z., Latash, M., Zatsiorsky. V.. 1998. Force sharing among fingers as a model of the redundancy problem. Exp. Brain Res. 119, 276 286.

Quaine, F., Martin, L., Blanchi, J.P., 1997. The effect of body position and number of supports on wall reaction forces in rock climbing. J. Appl. Biomech. 13, 14-23.

Rooks, M.. 1997. Rock climbing injuries. Sports Med. 23, 261-270,

Schweizer, A., 2001. Biomechanical properties of the crimp grip position in rock climbers. J. Biomech. 34, 217-223.

Sharkey, M., Smith, T., Zissimos, A., 1998. Pathomechanics of closed rupture of the flexor tendon pulleys in rock climbers. J. Bone Joint Surg. Am. 80, 1012-1019.

Valero-Cuevas, F.. Towles, J., Hentz, V.. 2000. Quantification of fingertip force reduction in the forefinger following simulated paralysis of extensors and intrinsic muscles. J. Biomech. 33, 16011609.

Zatsiorsky, V., Li, Z., Latash. M., 1998. Coordination force production in multi-finger tasks: finger interaction and neural network modeling. Biol. Cybern. 79, 139-150. 